\title{
Correlations between dentoskeletal variables and deep bite in Class II Division 1 individuals
}

\section{Leandro Silva Marques ${ }^{(a)}$ Mônica Costa Armond(a) Maria Letícia Ramos-Jorge ${ }^{(b)}$ Raquel Gonçalves Vieira de Andrade ${ }^{(b)}$ \\ Ana Maria Bolognese ${ }^{(c)}$}

(a) Department of Orthodontics, School of Dentistry, Vale do Rio Verde University (UNINCOR), Três Corações, MG, Brazil.

(b) Department of Pediatric Dentistry, School of Dentistry, Federal University of Vales do Jequitinhonha e Mucuri, Diamantina, MG, Brazil.

(c) Department of Orthodontics, School of Dentistry, Federal University of Rio de Janeiro, Rio de Janeiro, RJ, Brazil.

\author{
Corresponding author: \\ Leandro Silva Marques \\ R. Arraial dos Forros, 215 \\ Diamantina - MG - Brazil \\ CEP: 39100-000 \\ E-mail: Ismarques21@yahoo.com.br
}

Received for publication on Jun 23, 2010 Accepted for publication on Oct 12, 2010

\begin{abstract}
This study aimed to evaluate the cephalometric pattern of Class II Division 1 individuals with deep bite, and to determine possible correlations between dentoskeletal variables and deep bite. Comparisons were also made between genders and cases that were to be treated both with and without premolar extraction. A total of 70 lateral cephalograms were used, from both male $(\mathrm{n}=35)$ and female $(\mathrm{n}=35)$ individuals with an average age of 11.6 years, who simultaneously presented with ANB $\geq 5^{\circ}$ and overbite $\geq 4 \mathrm{~mm}$. Statistical analysis involved parametric (t-test) and non-parametric (Mann-Whitney) tests for independent samples, as well as the Spearman correlation test $(\mathrm{p} \leq 0.05)$. The values of Go-Me, Ar-Pog, PM-1 and PM-CMI were higher in males ( $\mathrm{p}<0.05)$. However, no significant differences were found among the averages of the cephalometric measurements when the sample was divided by treatment with and without extraction. Deep bite was positively correlated to the PM-1 and SNA measurements, and negatively correlated to the Go-Me, ArPog, SNB and SNGoMe measurements. The main factors associated with the determination of deep bite in Angle's Class II Division 1 cases were: greater lower anterior dentoalveolar growth and/or lower incisor extrusion, horizontal growth pattern, maxillary protrusion and mandibular retrusion.
\end{abstract}

Descriptors: Orthodontics; Malocclusion; Tooth Extraction; Radiography.

\section{Introduction}

The main factors involved with the establishment of Class II Division 1 malocclusion are: maxillary protrusion with normal mandibular position, mandibular retrusion with normal maxillary position, a combination of maxillary protrusion and mandibular retrusion, and posterior rotation of the mandible. ${ }^{1}$ In turn, deep bite has been related to a lack of vertical growth in the molar and premolar regions, and/or the supraeruption of incisors and canines. ${ }^{2-5}$

The treatment of Class II Division 1 malocclusion can be accomplished by several methods. ${ }^{6-10}$ Treatment considerations include the patient's facial profile, skeletal pattern, growth potential, and severity of the malocclusion. ${ }^{6}$ A deep overbite can be corrected by intrusion of anterior teeth or extrusion of posterior teeth, or a combination of both. ${ }^{10}$ Clockwise rotation of the mandible can also correct an anterior deep 
bite; however, it might lead to a more severe Class II molar relationship. ${ }^{6}$

In this context, the Class II Division 1 malocclusion with deep overbite may be linked to a combination of a large number of factors. Determining the individual influence of such factors provides a valuable resource for orthodontic diagnosis, and can make the difference between the success or failure of treatment.

Therefore, the present study proposes to evaluate the pre-treatment cephalometric pattern of Class II Division 1 individuals with deep bite, with particular attention to the identification of factors correlated to the determination of deep bite.

\section{Material and Methods}

The teleradiographs used in the present study were gathered from the orthodontic documentation collection of the Department of Orthodontics at the Federal University of Rio de Janeiro. The sample comprised 70 patients, 35 male and 35 female. Individuals had an average age of 11.6 years (minimum of 9.8 years and maximum of 14.9 years). The inclusion criteria were as follows:

- Simultaneous presence of Class II Division 1 malocclusion with $\mathrm{ANB} \geq 5^{\circ}$ and deep bite $\geq 4 \mathrm{~mm}$.

- Absence of any other type of prior treatment, as this could influence the vertical development of the alveolar process or the dimensions of the mid-face structures.

- All were Caucasian Brazilians, to avoid ethnic differences in the craniofacial morphology.

- All presented teleradiographs of satisfactory quality.

The sample was also divided according to the type of treatment to be carried out - with or without the extraction of four premolars.

Lateral teleradiographs were traced and measured by hand, by a single investigator (LSM), using a $17.5 \times 17.5 \mathrm{~cm}$ sheet of acetate (Ultraphan, Berlin, Germany), $0.5 \mathrm{~mm}$ Pentel mechanical pencil, protractor, square, eraser, and millimetric ruler (Faber Castell, São Carlos, Brazil). All radiographs were obtained using the same mobile X-Ray system (10 Orthoceph - Siemens, set to $62 \mathrm{KV}$ and $16 \mathrm{~mA}$, with exposure time of 1.3 seconds).
Thirteen cephalometric variables (8 linear and 5 angular) were catalogued as follows (Figures 1 and 2):

1. Overbite $(\mathrm{mm})$ : distance between the edges of the upper and lower incisors, perpendicular to the Downs facial plane.

2. Height of the mandibular ridge (Ar-Go): linear distance between the Articular and Gonion points.

3. Length of the mandibular body (Go-Me): linear distance between the Gonion and Menton points.

4. Total mandibular length (Ar-Pog): linear distance between the Articular and Pogonion points.

5. PP-1: Perpendicular distance in millimeters from the edge of the upper permanent incisor to the palatal plane.

6. PP-CMS: Perpendicular distance in millimeters from the mesiobuccal cusp of the first upper permanent molar to the palatal plane.

7. PM-1: Perpendicular distance in millimeters from the incisal edge of the lower incisor to the Steiner mandibular plane.

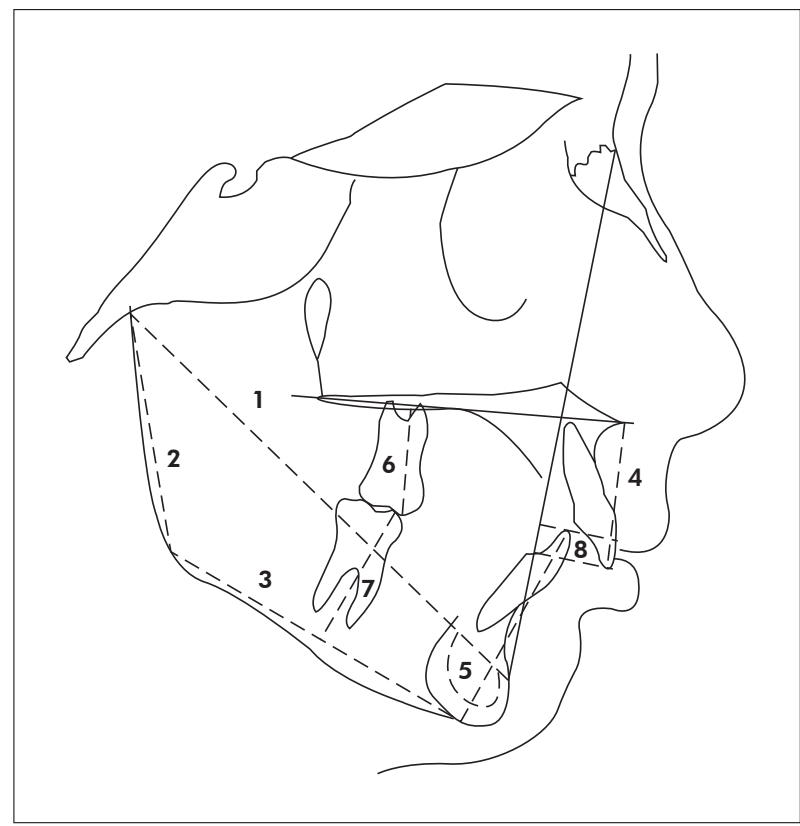

Figure 1 - Cephalometric landmarks, reference lines, and linear measurements used in the study. 1. Ar-Pog. 2. Ar-Go. 3. Go-Me. 4. PP-1. 5. PM-1. 6. PP-CMS. 7. PM-CMI. 8. Overbite. 


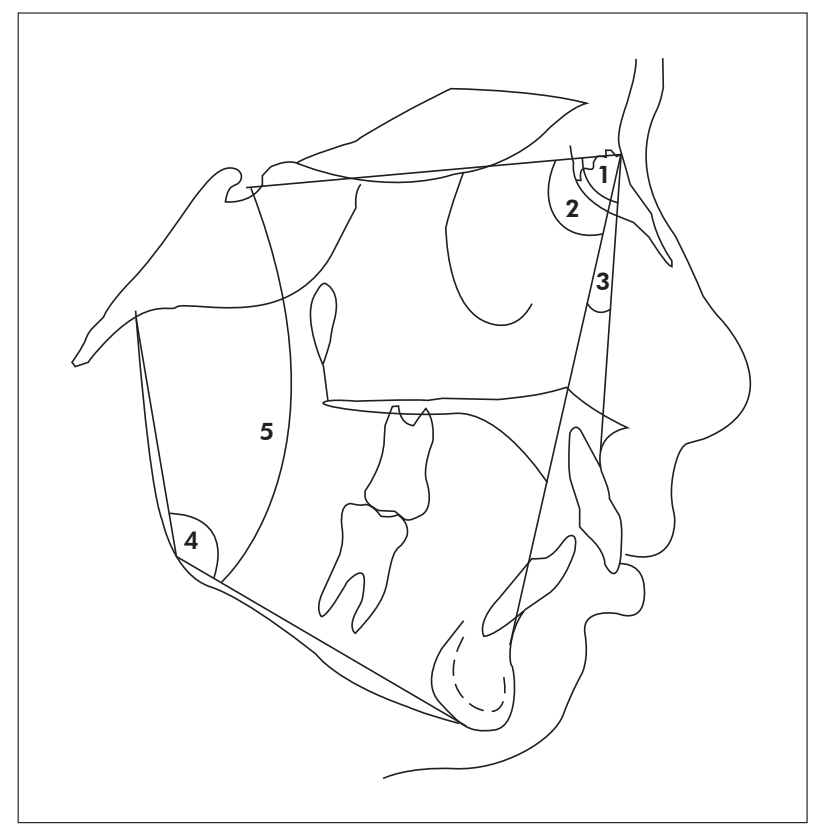

Figure 2 - Cephalometric landmarks, reference lines, and angular measurements used in the study. 1. SNA. 2. SNB. 3. ANB. 4. ArGo-Me. 5. SNGoMe.

8. PM-CMI: Perpendicular distance in millimeters from the mesiobuccal cusp of the first lower permanent molar to the Steiner mandibular plane.

9. Degree of protrusion or retrusion of the maxilla in relation to the base of the cranium - SNA: angle formed by the Sella-Nasion and Nasion lines - Point A.

10. Degree of protrusion or retrusion of the mandible in relation to the base of the cranium - SNB: angle formed by the Sella-Nasion and Nasion lines - Point B.

11. Anterior-posterior relation between the maxilla and mandible - ANB: angle formed by the SellaNasion and Nasion lines - Point B.

12. Gonial angle (ArGo-Me): angle formed by the Ar-Go and Go-Me lines.

13. Mandibular plane in relation to the base of the cranium (SNGoMe): angle formed by the mandibular plane (Go-Me) and the Sella-Nasion line. Statistical analysis was done using the Software Package for Social Sciences (SPSS for Windows, version 12.0, SPSS Inc., Chicago, IL, USA). The arithmetic average and standard deviation were calculated for each variable. The data obtained were submitted to a variance homogeneity test (Levene's test) and a normality test (Kolmogorov-Smirnov). Next, the variables that would be analyzed, using the parametric (T test) and non-parametric (MannWhitney) tests, were determined. The correlation of initial deep bite with the other variables was established using the non-parametric Spearman correlation test.

Three weeks after the initial records were taken, 20 teleradiographs were randomly selected, retraced and new measures were taken. Next, the $\mathrm{T}$ test for paired samples was applied. Differences between the first and second records of the 20 teleradiographs proved to be insignificant.

\section{Results}

Initially, we sought to determine if there were differences between genders regarding the cephalometric characteristics of Class II Division 1 malocclusion with deep bite. As Table 1 displays, significant differences appeared between the Go-Me $(\mathrm{p}=0.007), \operatorname{Ar}-\operatorname{Pog}(\mathrm{p}=0.009), \operatorname{PM}-1(\mathrm{p}=0.008)$ and PM-CMI ( $\mathrm{p}=0.047)$ measures. Table 1 also provides the average and standard deviation, as well as the minimum and maximum, of each cephalometric measurement proposed in the present study.

Table 2 displays the descriptive analysis and comparison of the cephalometric measurements according to treatment with or without the extraction of four premolars. This analysis confirms that there were no significant differences between the groups.

Table 3 displays the correlations between deep bite and the other cephalometric variables. A positive correlation was observed between deep bite and the PM-1 ( $\mathrm{p}=0.027)$ and SNA ( $\mathrm{p}=0.023)$ variables. Deep bite presented a negative correlation with the Go-Me ( $\mathrm{p}<0.001)$, Ar-Pog $(\mathrm{p}<0.001)$, SNB $(\mathrm{p}=0.005)$ and SNGoMe $(\mathrm{p}=0.034)$ variables.

\section{Discussion Overbite}

The difficulty of correcting deep bite has been recognized for decades. Over the years, opinions have differed regarding the etiology of this alteration and, consequently, regarding how it should be treated. ${ }^{11}$ This controversy can be explained by the lack of standardization among studies, thereby con- 
Table 1 - Descriptive analysis and comparison of pre-treatment cephalometric measurements according to gender.

\begin{tabular}{|c|c|c|c|c|c|c|c|c|c|c|}
\hline & & \multicolumn{8}{|c|}{ Descriptive statistics } & \multirow{3}{*}{$\mathrm{p}$-value } \\
\hline & & \multicolumn{2}{|c|}{ Mean } & \multicolumn{2}{|c|}{ SD } & \multicolumn{2}{|c|}{ Minimum } & \multicolumn{2}{|c|}{ Maximum } & \\
\hline & & M & $\mathrm{F}$ & M & $\mathrm{F}$ & M & $\mathrm{F}$ & M & $\mathrm{F}$ & \\
\hline \multirow{8}{*}{ 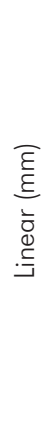 } & Overbite & 6.06 & 5.51 & 0.99 & 1.27 & 4.0 & 4.0 & 8.0 & 9.0 & $0.051^{\top}$ \\
\hline & Ar-Go & 40.34 & 40.71 & 4.70 & 3.85 & 32.0 & 33.0 & 51.0 & 49.0 & $0.719^{\top}$ \\
\hline & Go-Me & 67.66 & 64.80 & 4.27 & 4.32 & 60.0 & 58.0 & 79.0 & 75.0 & $0.007^{\top}$ \\
\hline & Ar-Pog & 103.09 & 99.60 & 5.66 & 5.08 & 94.0 & 91.0 & 117.0 & 111.0 & $0.009^{\top}$ \\
\hline & PP- 1 & 29.46 & 28.49 & 2.68 & 3.09 & 22.0 & 21.0 & 35.0 & 34.0 & $0.165^{\top}$ \\
\hline & PP-CMS & 21.74 & 21.43 & 1.57 & 2.45 & 18.0 & 17.0 & 25.0 & 29.0 & $0.595^{u}$ \\
\hline & PM- 1 & 42.40 & 40.40 & 3.34 & 2.73 & 33.0 & 34.0 & 50.0 & 45.0 & $0.008^{\top}$ \\
\hline & PM-CMI & 30.29 & 28.74 & 3.54 & 2.78 & 23.0 & 24.0 & 45.0 & 37.0 & $0.047^{\top}$ \\
\hline \multirow{5}{*}{ 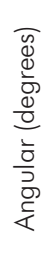 } & SNA & 83.77 & 82.51 & 4.38 & 3.74 & 74.0 & 72.0 & 95.0 & 91.0 & $0.202^{\top}$ \\
\hline & SNB & 76.46 & 75.77 & 4.18 & 3.72 & 67.0 & 69.0 & 87.0 & 82.0 & $0.471^{\top}$ \\
\hline & ANB & 7.31 & 6.7 & 2.05 & 2.32 & 4.50 & 4.50 & 12.0 & 12.0 & $0.279^{\top}$ \\
\hline & ArGo-Me & 131.00 & 130.69 & 5.47 & 5.47 & 120.0 & 121.0 & 143.0 & 144.0 & $0.811^{\top}$ \\
\hline & SNGoMe & 36.40 & 35.89 & 6.35 & 5.15 & 23.0 & 27.0 & 50.0 & 45.0 & $0.711^{\top}$ \\
\hline
\end{tabular}

Note: 35 male patients and 35 female patients. ${ }^{\top} \mathrm{p}$-value obtained through the T test for independent samples. ${ }^{U} \mathrm{p}$-value obtained through the Mann-Whitney test. F - Female. M - Male.

Table 2 - Descriptive analysis and comparison of pre-treatment cephalometric measurements according to treatment with and without extraction of four premolars.

\begin{tabular}{|c|c|c|c|c|c|c|c|c|c|c|}
\hline & & \multicolumn{8}{|c|}{ Descriptive statistics } & \multirow{3}{*}{$\mathrm{p}$-value } \\
\hline & & \multicolumn{2}{|c|}{ Mean } & \multicolumn{2}{|c|}{ SD } & \multicolumn{2}{|c|}{ Minimum } & \multicolumn{2}{|c|}{ Maximum } & \\
\hline & & $E$ & NE & $E$ & NE & $E$ & NE & $E$ & NE & \\
\hline \multirow{8}{*}{ 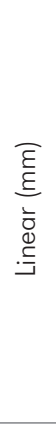 } & Overbite & 5.67 & 5.88 & 1.06 & 1.24 & 4.00 & 4.00 & 8.00 & 9.00 & $0.463^{\top}$ \\
\hline & Ar-Go & 39.63 & 41.20 & 3.79 & 4.52 & 32.00 & 33.00 & 47.00 & 51.00 & $0.130^{\top}$ \\
\hline & Go-Me & 65.73 & 66.60 & 4.41 & 4.59 & 58.00 & 60.00 & 79.00 & 77.00 & 0.429 \\
\hline & Ar-Pog & 100.70 & 101.83 & 5.44 & 5.77 & 91.00 & 93.00 & 113.00 & 117.00 & $0.411^{\top}$ \\
\hline & PP-1 & 28.87 & 29.05 & 3.22 & 2.69 & 21.00 & 22.00 & 35.00 & 34.00 & $0.797^{\top}$ \\
\hline & PP-CMS & 21.87 & 21.38 & 2.19 & 1.94 & 17.00 & 17.00 & 29.00 & 25.00 & $0.325^{\top}$ \\
\hline & PM- 1 & 41.97 & 40.98 & 2.48 & 3.60 & 37.00 & 33.00 & 46.00 & 50.00 & $0.200^{\top}$ \\
\hline & PM-CMI & 29.30 & 29.68 & 2.69 & 3.65 & 23.00 & 24.00 & 37.00 & 45.00 & $0.637^{\top}$ \\
\hline \multirow{5}{*}{ 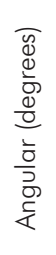 } & SNA & 82.90 & 83.33 & 4.02 & 4.19 & 74.00 & 72.00 & 91.00 & 95.00 & $0.671^{\top}$ \\
\hline & SNB & 75.70 & 76.43 & 3.87 & 4.01 & 67.00 & 70.00 & 82.00 & 87.00 & $0.451^{\top}$ \\
\hline & ANB & 7.20 & 6.90 & 1.99 & 2.35 & 4.5 & 4.5 & 12.00 & 12.00 & $0.575^{\top}$ \\
\hline & ARGo-Me & 131.53 & 130.32 & 6.03 & 4.96 & 120.00 & 121.00 & 144.00 & 143.00 & $0.361^{\top}$ \\
\hline & SNGoMe & 37.17 & 35.38 & 5.72 & 5.71 & 26.00 & 23.00 & 50.00 & 47.00 & $0.199^{\top}$ \\
\hline
\end{tabular}

Note: 30 patients treated with extraction and 40 without extraction. ${ }^{\top} p$-value obtained through the T test for independent samples. E - Extraction. NE - Non extraction. 
Table 3 - Coefficient of Spearman correlation between deep bite and other cephalometric measurements, for all 70 cases of the sample.

\begin{tabular}{|c|c|c|c|}
\hline \multirow{2}{*}{\multicolumn{2}{|c|}{ Cephalometric Measurements }} & \multicolumn{2}{|c|}{ Spearman Correlation } \\
\hline & & \multirow{2}{*}{$\begin{array}{c}\text { Coefficient } \\
0.214\end{array}$} & \multirow{2}{*}{$\frac{p \text {-value }}{0.076}$} \\
\hline \multirow{7}{*}{$\begin{array}{l}\bar{\varepsilon} \\
\underline{\varepsilon} \\
\overline{\bar{z}} \\
\stackrel{\Xi}{\Xi}\end{array}$} & Ar-Go & & \\
\hline & Go-Me & -0.458 & $<0.001$ \\
\hline & Ar-Pog & -0.496 & $<0.001$ \\
\hline & PP-1 & 0.020 & 0.867 \\
\hline & PP-CMS & 0.099 & 0.415 \\
\hline & PM- 1 & 0.264 & 0.027 \\
\hline & PM-CMI & 0.035 & 0.776 \\
\hline \multirow{5}{*}{ 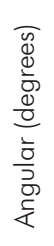 } & SNA & 0.272 & 0.023 \\
\hline & SNB & -0.335 & 0.005 \\
\hline & ANB & -0.149 & 0.220 \\
\hline & ARGo-Me & -0.021 & 0.864 \\
\hline & SNGoMe & -0.254 & 0.034 \\
\hline
\end{tabular}

fusing the interpretation of results and their clinical applications. Thus, the present study offers a singular advantage over others found in the literature due to the size and homogeneous nature of the selected sample. Only Class II Division 1 cases with deep bite were included. Furthermore, the sample is larger than that of any previous study found in the literature, enabling it to be divided into subgroups (gender, and treatment with or without extraction).

The manifestation of deep bite presented no significant difference between genders. This result confers homogeneity to the sample, and is in agreement with results found by Simons and Joondeph. ${ }^{12}$

Furthermore, no significant differences were observed among the averages of deep bite regarding the cases that were to be treated, either with or without the extraction of four premolars. This result demonstrates that the magnitude of pre-treatment overbite exercised no influence over the decision for treatment, either with or without extraction. A number of authors ${ }^{12-15}$ also corroborate the principle that pre-treatment deep bite per se does not necessarily counter-indicate an extraction approach. However, all authors state that such a principle is valid only as long as treatment is performed with planning and adequate mechanics.
When the 70 cases were evaluated together, it was observed that deep bite was positively correlated to the PM-1 and SNA measurements, and negatively correlated to the Go-Me, Ar-Pog, SNB, and SNGoMe measurements. The interpretation of these results suggests that deep bite in Class II Division 1 individuals is principally related to greater dentoalveolar growth in the lower incisor region and/ or the extrusion of these teeth. ${ }^{1,11}$ Furthermore, it is also related to the pattern and amount of maxillarymandibular growth; overbite is more pronounced when there is more horizontal growth and less mandibular growth. ${ }^{1}$ In summary, the results from the present study support the conclusion that the more severe the Class II Division 1 malocclusion is, the greater the chances are of developing deep bite. These findings corroborate findings by Bjork ${ }^{16}$ that the development of deep bite depends on the relation between the upper and lower incisors: if the lower incisor has adequate contact with the lingual surface of the permanent upper incisor, there is less chance of developing deep bite. Other authors also consider the supra-eruption of lower incisors to be a determinant factor for deep bite. ${ }^{17-20}$ Lewis, ${ }^{21}$ Steadman ${ }^{22}$ and Popovich ${ }^{23}$ attribute the occurrence of deep bite to a lack of vertical growth in the molar and premolar regions.

\section{Class II}

An evaluation of the results from the pre-treatment phase of the present study suggests there is a common dentoskeletal pattern among males and females regarding Class II Division 1 characterization and deep bite (Table 1). Although there were statistically significant differences in the total length of the mandible (Ar-Pog) and the length of the mandibular body (Go-Me), these were relative differences: there were in fact no significant differences among the principal determinant Class II factors (SNA, SNB and ANB). Another relevant aspect is that there were also no significant differences among the averages of the mandibular plane angle (SNGoMe), suggesting that the spatial configuration of the mandible is similar between male and female subjects in the determination of a Class II Division 1 malocclusion with deep bite. These results differ from 
those found by Lima-Filho et al., ${ }^{24}$ who identified significant differences between the genders regarding the SNA and ANB angle; however, the findings are in agreement with these same authors regarding the angle of the mandibular plane (SNGoMe). It is worth noting that the sample Lima-Filho et al. ${ }^{24}$ used comprised 40 Class II Division 1 patients, but these patients did not present with deep bite. In the literature researched, there were no studies found that allow comparisons with ours.

Another relevant observation, made from the results of the present study in regard to Class II Division 1 , was the absence of significant differences between the group to be treated without extraction and the group to be treated with extraction (Table 2). These results clearly indicate that the parameters used in the definition of the diagnosis and consequent treatment plan were associated mainly with dental aspects, most likely the amount of crowding, as the dentoskeletal characteristics were similar for both groups. These findings were not expected, and once again reveal an exclusive pattern regarding the characteristics and approach to the Class II Division 1 malocclusion with deep bite. In this context, it is important to compare the results from this study to those found by Basciftci and Usumez, ${ }^{25}$ who observed that the Class II Division 1 group was different with regard to various parameters before treatment. The pre-treatment values showed a more divergent growth pattern and more proclined incisors among the group treated with extraction, and a smaller mandibular body with greater overjet and overbite among the group treated without extraction. The differences between the results of these two studies can be explained by the fact that the Basciftci and Usumez ${ }^{25}$ study used just Class II Division 1 cases without deep bite (initial overbite in the group treated with extraction had an average of just

\section{References}

1. Proffit WR, Fields HW, Sarver DM. Contemporary Orthodontics. $4^{\text {th }}$ ed. St Louis: Mosby Elsevier; 2007. 751 p.

2. Hering K, Ruf S, Pancherz H. Orthodontic treatment of openbite and deepbite high-angle malocclusions. Angle Orthod. 1999 Oct;69(5):470-7.
$1.44 \mathrm{~mm})$. Furthermore, the initial records of the patients treated with extraction showed an average age of 17.5 years.

In this study, eight patients were in the mixed dentition stage and the second molars had not yet erupted. Since the average overbite was $6.06( \pm 0.99)$ in males and 5:51 ( \pm 1.27$)$ in females (Table 1), the authors do not believe that including these patients would influence the results of this study. Additionally, longitudinal evaluation developed by Bergensen ${ }^{26}$ shows that overbite decreases with the eruption of second molars and subsequent eruption of third molars by an average of 0.58 ( $\pm 1.06 \mathrm{~mm})$, decreasing the amount of the gap from $4: 34( \pm 1.18 \mathrm{~mm})$ to $3.76 \mathrm{~mm}( \pm 1.39 \mathrm{~mm})$.

A critical analysis of the literature reveals that most studies do not address pre-treatment dentoskeletal characteristics in a specific manner. They state that that this is not the main focus of the study, and omit data that would certainly contribute significantly to a more precise diagnosis of the factors involved in the determination of a Class II Division 1 malocclusion with deep bite.

\section{Conclusions}

- The Class II Division 1 malocclusion with deep bite developed in a different manner among males and females.

- The severity of Class II Division 1 and deep bite had no influence on the treatment option, with or without the extraction of premolars, among the sample studied.

- The main factors associated with the determination of deep bite were: greater lower anterior dentoalveolar growth and/or lower incisor extrusion, horizontal growth pattern, maxillary protrusion and mandibular retrusion.

3. Kim TW, Little RM. Postretention assessment of deep overbite correction in Class II Division 2 malocclusion. Angle Orthod. 1999 Apr;69(2):175-86. 
4. Hammond AB $3^{\text {rd }}$. Treatment of a Class II malocclusion with deep overbite. Am J Orthod Dentofacial Orthop. 2002 May;121(5):531-7.

5. Van Steenbergen E, Burstone CJ, Prahl-Andersen B, Aartman IH. The role of a high pull headgear in counteracting side effects from intrusion of the maxillary anterior segment. Angle Orthod. 2004 Aug;74(4):480-6.

6. Marques LS, Ramos-Jorge ML, Araujo MT, Bolognese AM. Class II Division 1 malocclusion with severe overbite: cephalometric evaluation of the effects of orthodontic treatment. World J Orthod. 2008 Winter;9(4):319-28.

7. Siara-Olds NJ, Pangrazio-Kulbersh V, Berger J, Bayirli B. Long-term dentoskeletal changes with the Bionator, Herbst, Twin Block, and MARA functional appliances. Angle Orthod. $2010 \mathrm{Jan} ; 80(1): 18-29$.

8. Janson G, Camardella LT, Araki JD, de Freitas MR, Pinzan A. Treatment stability in patients with Class II malocclusion treated with 2 maxillary premolar extractions or without extractions. Am J Orthod Dentofacial Orthop. 2010 Jul;138(1):1622.

9. Garbui IU, Nouer PR, Nouer DF, Magnani MB, Pereira Neto JS. Cephalometric assessment of vertical control in the treatment of class II malocclusion with a combined maxillary splint. Braz Oral Res. 2010 Jan-Mar;24(1):34-9.

10. Woods MG. Sagittal mandibular changes with overbite correction in subjects with different mandibular growth directions: late mixed-dentition treatment effects. Am J Orthod Dentofacial Orthop. 2008 Mar;133(3):388-94.

11. Hans MG, Kishiyama C, Parker SH, Wolf GR, Noachtar R. Cephalometric evaluation of two treatment strategies for deep overbite correction. Angle Orthod. 1994 Aug;64(4):265-74.

12. Simons ME, Joondeph DR. Change in overbite: a ten-year postretention study. Am J Orthod. 1973 Oct;64(4):349-67.

13. Magill JM. Changes in the anterior overbite relationship following orthodontic treatment in extraction cases. Am J Orthod. 1960 Oct;46(10):755-88.
14. El-Mangoury NH. Orthodontic relapse in subjects with varying degrees of anteroposterior and vertical dysplasia. Am J Orthod. 1979 May;75(5):548-61.

15. Burzin J, Nanda R. The stability of deep overbite correction. In: Nanda R, Burstone CJ, editors. Retention and stability in orthodontics. $1^{\text {th }}$ ed. Philadelphia: Saunders; 1993. p. 61-80.

16. Bjork A. Prediction of mandibular growth rotation. Am J Orthod. 1969 Jun;55(6):585-99.

17. Strang RHW. An analyses of the overbite-problem malocclusion. Angle Orthod. 1934 Jan;4(1):65-84.

18. Kim YH. Overbite depth indicator with particular reference to anterior open-bite. Am J Orthod. 1974 Jun;65(6):586-611.

19. Fleming HB. An investigation of the vertical overbite during the eruption of the permanent dentition. Angle Orthod. 1961 Jan;31(1):53-62.

20. Samuelson G, Garner LD, Potter R. Tooth movements associated with deep overbite correction in class II division 1 malocclusions. Int J Orthod. 1989 Fall-Winter;27(3-4):3-8.

21. Lewis P. Correction of deep anterior overbite. A report of three cases. Am J Orthod Dentofacial Orthop. 1987 Apr;91(4):3425 .

22. Steadman SR. Overbites and overjets. Angle Orthod. 1974 Apr;44(2):156-61.

23. Popovich F. Cephalometric evaluation of vertical overbite in young adults. J Can Dent Assoc. 1955 Apr;21(4):209-22.

24. Lima-Filho RM, Lima AL, Oliveira Ruellas AC. Longitudinal study of anteroposterior and vertical maxillary changes in skeletal class II patients treated with Kloehn cervical headgear. Angle Orthod. 2003 Apr;73(2):187-93.

25. Basciftci FA, Usumez S. Effects of extraction and nonextraction treatment on class I and class II subjects. Angle Orthod. 2003 Feb;73(1):36-42.

26. Bergersen EO. A longitudinal study of anterior vertical overbite from eight to twenty years of age. Angle Orthod. 1988 Jul;58(3):237-56. 